\title{
THEORIES OF LANGUAGE ACQUISITION IN RELATION TO BEGINNING READING INSTRUCTION ${ }^{1}$
}

\author{
Ronald Wardhaugh \\ University of Michigan
}

\begin{abstract}
Various theories of language acquisition are discussed: behavioristic, nativistic, and cognitive. Linguistically-oriented theories are compared with learning-oriented theories, and four controversial issues of frequency of stimuli, imitation, expansion, and meaning are reviewed. The theories are all rather unsubstantial at present. Reading acquisition seems to be very different from language acquisition, and the theories of language acquisition appear to have little to offer anyone in coming to a better understanding of how beginning reading should be taught.
\end{abstract}

\section{INTRODUCTION}

Numerous summaries of research in language acquisition exist: McCarthy (1954) summarizes work completed prior to 1950; Elkonin (1958), Brown and Berko (1960), Carroll (1960), Brown (1965), ErvinTripp (1966), Ervin-Tripp and Slobin (1966), McNeill (1966, 1970a, $1970 \mathrm{~b}$ ), and Slobin (1967) summarize parts, or the whole, of more recent work; and Kelley (1967) provides one of the most interesting discussions of many of the major issues. The purpose of this paper is to isolate and assess major theories of language acquisition and to relate these theories to beginning reading instruction. The particular focus is the acquisition of syntax. The theories are also reviewed from the perspective of the linguistic knowledge available today; consequently, certain cognitive and affective factors are minimized. These factors are not to be considered unimportant in beginning reading instruction; rather they are to be considered beyond the scope of this paper.

\section{LANGUAGE ACQUISITION}

Atheoretical Studies

A reading of McCarthy's summary article induces mixed feelings in anyone trained in linguistics. She reports on a wide variety

1Preparation of this paper was supported through an Office of Education Contract OEC-0-70-4790 (508) to Rutgers, The State University. The author is grateful to Patricia Dishuck and Mary Ann Gatten for their assistance. 
of descriptive and normative studies, but all seem unrevealing insofar as current interests in language acquisition are concerned. The studies reported appear atheoretical today because the investigators made little attempt to formulate and test fruitful hypotheses and to handle data other than quantitively. Consequently, no coherent account of language acquisition emerges from the studies reviewed by McCarthy. Instead, child language appears to drift somehow from a prevocalic stage, through various stages replete with errors and deficiencies, toward the clearly articulated speech of an ideal speaker of Standard English. As a result, sounds "emerge" in ways that are never specified, "first words" are uttered at a characteristic time, grammatical distinctions are "acquired," often through the elimination of various "errors," and vocabularies "expand" as the child's dictionary gains more entries. Gradually, by some process of making successive approximations, the child's language becomes more and more like the language ascribed in traditional grammars to those who speak the language "properly."

Working in such a way, investigators may try to discover when the child learns to distinguish pin from pen and witch from which, all the while ignoring the fact that in certain dialects such distinctions are not made at all. Or they may try to count various sentence types using formulae for sentence description that derive from analyses of writing and studies of rhetorical devices rather than from any close observation of spoken language. Or they may calculate word frequencies and compute type-token ratios without defining the concept of "a word" or devising the most appropriate elicitation procedures. Such investigators often collect considerable quantities of data which can be neatly inventoried and displayed in tables and figures (for example, tables of errors in articulation which show a gradual reduction in frequency as age increases). However, the data are essentially unrevealing because the investigators do not ask why it is that one linguistic skill is acquired before another, or what is the nature of the linguistic ability of the child at various stages in his linguistic development.

Only in recent years have such questions been asked by psychologists and linguists engaged in the study of language acquisition. They have realized that inventories are unrevealing unless they show which items contrast with each other within the inventories. They no longer disregard regional and social variations in speech and developments in modern linguistics. They insist that it is impossible to describe language acquisition without first spelling out either a specific theory of language or a general theory of learning. Recent work on language acquisition therefore confronts these theoretical issues. It does so at the expense of large scale data 
collection, investigators preferring to test out hypotheses on as few as two or three children, as Brown and Bellugi (1964) did with Adam and Eve, or on a single phonological, grammatical, or semantic distinction, as Klima and Bellugi (1966) did with negation.

One issue that has never been dealt with satisfactorily, even in recent work, is the specification of the ultimate linguistic knowledge or ability that is being acquired. Obviously, more is involved than knowledge of a dictionary or of an inventory of sentence patterns, or the ability to combine words and patterns. N. Chomsky (1965) has proposed the term competence, as distinguished from performance, to describe this knowledge. However, this term has become more of a slogan than a well-defined concept in linguistics. Since research in language acquisition must focus on such issues as "increasing complexity" and "developing competence," a certain vagueness results when the end-point toward which the child is assumed to be progressing still remains largely hidden from view. Menyuk (1969) discusses some of the problems that result in attempts to interpret data in such circumstances. Fortunately, many of the data are not in dispute among those who study language acquisition, for all agree that certain stages or trends can be observed: babbling ends around 18 months; holophrastic utterances precede two- and three-word utterances; early speech is "telegraphic"; control of word order antedates control of inflections; and comprehension outstrips production. The interpretation of the data is the crucial issue.

\section{Behavioristic Theories}

In his book Verbal Behavior (1957), Skinner proposes a comprehensive theory of language acquisition and language behavior in which specific linguistic behaviors are acquired through operant conditioning and then extended through response generalization. N. Chomsky's devastating review (1959) of the book demonstrates the inappropriateness of Skinner's proposal. His criticisms reiterate earlier arguments from Syntactic Structures (1957) that existing theories of language are inadequate for almost any purpose and that the kind of theory he himself proposes is needed. The review also attacks the adequacy of reinforcement theory and the notion of generalization, as formulated by Skinner, in explaining either language acquisition or language behavior. Chomsky claims that the theory is illusionary, that most of its concepts are irrelevant in explaining linguistic behavior, and that the real issues are never confronted. Chomsky is particularly critical of Skinner's failure to recognize the contribution the child makes to language acquisition, declaring that: 
... a refusal to study the contribution of the child to language learning permits only a superficial account of language acquisition, with a vast and unanalyzed contribution attributed to a step called 'generalization' which in fact includes just about everything of interest in this process. If the study of language is limited in these ways, it seems inevitable that major aspects of verbal behavior will remain a mystery. (1959:58)

However, in spite of Chomsky's criticisms of the inadequacy of conditioning or reinforcement theories to explain language acquisition such theories are still proposed. Staats and Staats (1962, 1963, 1968), for example, use such terms as operant learning, reinforcing stimuli, time and scheduling of reinforcement, successive approximation, chaining, extinction, and discrimination and generalization to explain how language is acquired. Such concepts can only weakly explain why all children exhibit much the same pattern of development, how they construct novel utterances even in the earliest days of language use, and in what ways they master the abstract relationships that are not readily apparent in the utterances they hear. This last point is extremely important because, as Garrett and Fodor (1968) argue, the facts of language are abstractions which children must acquire from masses of highly variable data. Language is a mentalistic phenomenon, and S-R theories are unable to account for either its acquisition or use. The theory proposed by Staats and Staats involves the learning of a finite set of responses according to certain probabilities of occurrence. On the other hand, the current view is that a language is an infinite set of responses that are available to a speaker, and that language use is essentially creative. Probability has little to do with language use, although, of course, certain linguistic usages can be conditioned to events in the world once such usages have been acquired.

Jenkins and Palermo (1964) propose a theory of language acquisition that recognizes some recent linguistic advances. The basic problem they see in language acquisition is that of explaining how the child acquires the frames of a phrase-structure grammar and the ability to substitute items within these frames. They propose that the child learns the stimulus and response equivalences that can occur in the frames. They heavily emphasize imitation, either overt or covert, as a force in establishing bonds between stimuli and responses, and they claim that the child generalizes to form classes of responses. However, they do not explain how control of such classes allows the child to construct longer sentences. Their theory does not attempt to analyze complex issues; it merely hints at them. The linguistic theory that Jenkins and Palermo 
propose is one N. Chomsky (1957) criticizes for being inadequate in that it does not account for the abstract nature of linguistic knowledge. Weksel (1965) is also critical of their proposal, claiming that it is linguistically inadequate and nowhere comes to grips with its central concept of generalization.

Another theory of language acquisition cast in the behavioristic mold comes from Braine (1963a, 1963b, 1965). This theory involves the principle of "contextual generalization," according to which the child observes that certain sets of items occur in certain positions. He makes generalizations about positions rather than about the sets of items that occupy them. The positions themselves are not simply linear, but may be hierarchical. Consequently, the theory attempts to explain how the child acquires the hierarchical grammatical structures of sentences. Braine claims that transformations can be learned through contextual generalization. If they cannot, he declares that the failure argues as much for a reshaping of linguistic theory as it does for a reshaping of the principle of contextual generalization:

If there is a possibility that the simpler of two possible grammatical solutions might require the more complex acquisition theory, then the domain over which simplicity is taken cannot be restricted to grammar alone and must include acquisition theory-otherwise the grammarian merely purchases simplicity at the psychologist's expense. (1965:491).

Slobin (in press) objects to Braine's proposal, citing evidence from a variety of languages. Bever, Fodor, and Weksel (1965a, $1965 \mathrm{~b})$, argue that no dominant patterns of word order exist for the child to generalize from, even in a language such as English, and that word ordering also occurs during language acquisition when the language has free word order. They say that the child must learn abstract structures for which no word order patterns exist in the data to which he is exposed. Answering this last criticism, Braine (1965) points out that data do exist and that closer attention must be paid to how the child uses these data in the process of acquiring language.

\section{Nativist Theories}

Lenneberg (1967) proposes a theory of language acquisition heavily buttressed by biological evidence from studies of normal language development in children and of abnormal language development brought about congenitally, as in nanocephalic dwarfism, or environmentally, as in brain damage or aphasia. He emphasizes the development of the organism's capacities and shows how these 
mature along a fairly fixed schedule. Language emerges during this maturational process when anatomical, physiological, motor, neural, and cognitive developments allow it to emerge. Every child must learn the specific details of the language of his community, but the ability to learn language is innate and part of the biological endowment of the organism. The learning mechanisms, such as certain modes of perception, abilities in categorization, and capacities for transformation, are biologically given. According to Lenneberg, the child "resonates" to the language of his environment during the acquisition process; however, he never clearly specifies exactly what resonance is. One of Lenneberg's most interesting observations is that there is a critical, biologically-determined period for language acquisition between the ages of two and twelve.

Since Lenneberg is interested in the biological bases of language acquisition, he has almost nothing to say about how particular linguistic items are learned, except to deny that statistical probability and imitation are important in the process. He claims that language acquisition is a natural activity, much as learning to walk is a natural activity. Both activities occur universally unless a pathological condition exists. Learning, as this term is traditionally defined, is not involved. Instead, Lenneberg carefully locks language acquisition into the general biological development of the organism.

McNeill (1966, 1968, 1970a, 1970b) takes a rather different nativist position toward language acquisition. He says that anyone who wishes to study the problem of language acquisition must begin with a knowledge of what it is that the child must acquire:

A major requirement for any theory of language acquisition is that it explain a known phenomenon, which means that theories of development must be related to particular grammatical analyses, to particular theories about language itself. (1968:406)

McNeill claims that the child must acquire a generative-transformational grammar. Following N. Chomsky (1957, 1965), he asks what intrinsic properties must a device, a Language Acquisition Device (LAD), possess to acquire such a grammar from the corpus of utterances to which it is exposed:

LAD is, of course, a fiction. The purpose in considering it is to discuss real children, not abstract ones. We can accomplish this because LAD and children present the same problem. LAD is faced with a corpus of utterances from which it develops a grammar on the basis of some kind of internal structure. So do children. We can readily posit that children and LAD arrive at the same grammar from the same corpus, and stipulate that 
children and LAD therefore have the same internal structure, at least within the limits that different children may be said to have the same internal structure. Accordingly, a theory about LAD is ipso facto a theory about children. (1970a:71)

The child must possess certain innate abilities, otherwise it is impossible to explain how the random, finite linguistic input into the child results in the output of linguistic competence.

According to McNeill, one innate property of the LAD is the ability to distinguish speech sounds from other sounds in the environment. A second property is the ability to organize linguistic events into various classes which can later be refined. This ability allows for the development of both the phonological and syntactic systems. One of the innate organizing principles is the concept of the "sentence." A third innate property is knowledge that only a certain kind of linguistic system is possible and that other kinds are not. McNeill claims that the child is born with an innate knowledge of linguistic universals. He distinguishes (1970a) between what he calls "weak" linguistic universals (reflections in language of universal cognitive abilities) and "strong" linguistic universals (reflections in language of specific linguistic abilities). He is more interested in the latter and seems skeptical of any claims advanced by cognitive theorists about the former. A fourth property is the ability to engage in constant evaluation of the developing linguistic system so as to construct the simplest possible system out of the linguistic data that are encountered.

In an attempt to justify his position, McNeill attacks S-R theory on the grounds that language acquisition is beyond its domain:

Because $S-R$ theory is so limited, the problem of language acquisition simply falls beyond its domain. This in itself is not a serious matter. Not all psychological theories need account for language acquisition. More serious, however, is the fact that the application of S-R principles causes theorists to redefine language in such a way as to make the phenomenon fit the theory. There is perhaps some irony in this outcome of modern empiricism. (1968:412)

McNeill also argues against the importance of the frequency of stimuli in language acquisition, using examples from Japanese, and against the importance of imitation. He claims that theories requiring imitation fail to explain why only certain responses occur. He criticizes Braine for ignoring the essential transformational nature of grammatical structure. Moreover, to Lenneberg's notion of a biological foundation for language, he adds a strong cognitive "content" component in the form of a structure for the mind that 
allows only certain kinds of language learning to occur. The organism has the capacity to learn and to generalize, but must realize this capacity within certain innate constraints that are suggested by a particular linguistic theory.

McNeill actually says very little about the mechanisms of acquisition. In addition, his claim that in the earliest stages the child speaks in the universal base structures of a generative-transformational grammar may not be linguistically sound. His further claim that the child "honors" grammatical distinctions before actually making them has been attacked as invalid by Bloom (in press).

Cognitive Theories

Like Fodor (1966), Slobin (1966a, 1966b) does not subscribe to nativistic theories of language acquisition. He says:

It seems to me that the child is born not with a set of linguistic categories but with some sort of process mechanism-a set of procedures and inference rules, if you will-that he uses to process linguistic data. (1966b:87-88)

Slobin regards language acquisition as an active process in which certain abilities of the child develop. One is the cognitive ability to deal with the world; a second is the mental ability to retain items in short term memory, to store items in long term memory, and to process information increasingly with age. The developments control the pace of language acquisition. Others are important too, such as the ability to segment utterances into sounds and meanings, and then to combine and recombine these segments, the ability to isolate meaning units, and the ability to make wide generalizations before attempting to accommodate exceptions. However, according to Slobin, general cognitive and mental development is the critical determinant of language acquisition.

Slobin marshals evidence from a variety of languages to support his position that language acquisition is one kind of general development, and that the general principles involved in the latter must be recognized. He differs from McNeill in the way he uses linguistic data. McNeill uses such data to postulate the presence of innate linguistic principles; Slobin uses the same data to support innate principles of cognition. For example, in discussing McNeill's proposal concerning the child's innate knowledge of substantive linguistic universals, Slobin says:

Perhaps all that is needed is an ability to learn certain types of semantic or conceptual categories, the knowledge that learnable semantic criteria can be the basis for grammatical categories, 
and, along with this substantive knowledge, the formal knowledge that such categories can be expressed by such morphological devices as affixing, sound alternation, and so on. The child's 'preprogramming' for substantive universals is probably not for specific categories like past, animate, plural, and the like, but consists rather of the ability to learn categories of a certain as-yetunspecified type. (1966b:89)

Slobin differs from the behaviorist theories in that he is a cognitivelearning theorist who regards the human learner as an active participant in learning rather than as a relatively passive reactor to external stimuli:

The important advances in language development thus seem to be tied to such variables as increasing ability to perform a number of operations in a short time, increasing short-term memory span, and increasing cognition of the categories and processes of human experience. In fact, it may be that strictly linguistic acquisition is completed by age three or so. Further development may reflect lifting of performance restrictions and general cognitive growth, without adding anything basically new to the fundamental structures of syntactic competence. We have begun to gather data on the earliest stages of language development. We have very little data on later stages. And our understanding of the mental processes underlying the course of this development is extremely rudimentary indeed. At this point $I$ believe we are in need of much more data on children's acquisition of various native languages....

Cromer (1968) provides further evidence of the role of cognitive abilities in determining the language the child can use. From a study of the development of temporal reference in two children over a four-year period, he notes that several new types of reference to points in time begin to occur regularly at about the age of 4 to $4 \frac{1}{2}$ for each child. Viewed together, these new forms indicate that the child has greatly expanded his range of temporal reference and increased his sense of the possible relations between times. Cromer notes that the ability develops to express events out of chronological order, to make statements about possibility, and to relate one time to another time. He hypothesizes that a single factor alone accounts for the observed linguistic changes: the child suddenly finds that he can free himself from the immediate situation and the actual order of events and can imagine himself at other points in time and view events from that perspective. This increase in his cognitive ability enables him to express new meanings, and he immediately masters the necessary syntactic apparatus to do so. 
There are even stronger claims for a cognitive basis to language acquisition than those made by Slobin. Schlesinger (in press) claims that linguistic structures are ". . . determined by the innate cognitive capacity of the child,"' and Sinclair-de-Zwart (1968) claims that "Iinguistic universals exist precisely because thought structures are universal." However, no empirical evidence apparently exists to confirm either claim.

Linguistically-oriented Theories Versus Learning-oriented Theories

In trying to develop a theory of language acquisition, an investigator is faced with a fundamental decision concerning a starting point. Should he begin by accepting certain principles from linguistics or certain principles from psychology? In other words, should he begin by saying, as McNeill does, that what must be explained is how the child acquires a generative-transformational grammar, or by saying, as Staats and Staats do, that a behavioristic theory employing such principles as association-formation and stimulus and response generalization should be able to account for language acquisition? McNeill proceeds to dismiss current learning theories as inadequate to explain the special behavior or knowledge which he claims comprises linguistic competence, and Staats and Staats proceed to ignore certain kinds of linguistic data.

Braine attempts to fasten on to the best in both linguistic theory and learning theory. He claims that each must, if necessary, be changed to accommodate the other. The two extremes of the general positions taken by McNeill and Staats and Staats are probably equally untenable, for at one extreme the interest is basically in the linguistic description of child language with very little concern for learning principles, and at the other extreme the interest is in applying learning principles derived from experiments with animals to the one behavior that no animal exhibits, linguistic behavior. Neither McNeill nor Staats and Staats take these extreme positions, but sometimes they seem to be approaching them. In the circumstances, Braine's middle ground may appear to be more attractive; however, both linguists and learning theorists find his proposed compromises unacceptable.

Fodor acknowledges the necessity for postulating some innate structure without committing himself as to whether this structure derives from innate linguistic principles or innate learning principles:

... the child must bring to the language learning situation some amount of intrinsic siructure. This structure may take the form of general learning principles or it may take the form of relatively detailed and language-specific information about the kind of 
grammatical system that underlies natural languages. But what cannot be denied is that any organism that extrapolates from its experience does so on the basis of principles that are not themselves supplied by the experience. (1966:106)

Slobin's position is less equivocal. He considers the child to be endowed with the cognitive capacity to perform extremely complicated tasks. The child accomplishes the complicated task of language acquisition according to general laws of development, learning, and perception. Consequently, he brings a particular capacity to the task rather than knowledge of a set of innate linguistic principles.

\section{Four Controversial Issues}

It is of interest to examine how various theories deal with the problems of the frequency of stimuli, the place of imitation, the role of expansion, and the function of meaning in language acquisition. In this way the theories can be shown to differ in certain important respects, and some preliminary assessment can be made of their relevance to beginning reading instruction.

The relative frequency of stimuli must be important in any behavioristic theory of learning. The most frequently occurring words and structures in the language should be acquired first by the child. However, the empirical evidence of language acquisition contradicts this expectation. Telegraphic speech, for example, omits the most frequently occurring words in the language, and investigators agree that every child goes through a "telegraphic" stage. There must be some reason for the existence of such speech, but it appears to have little to do with the frequency of stimuli in the environment.

Mc Neill $(1966,1968)$ also argues that Japanese children acquire a less frequent grammatical marker $g a$ before a more frequent marker $w a$ because $g a$ is important as a deep subject marker whereas $w a$ is not. He later (1970a:30-31) offers a rather different interpretation of the same data in accordance with the kinds of predicates (intrinsic with $w a$ and extrinsic with $g a$ ) that the child is capable of forming at the age when wa and ga appear in speech. Slobin (in press) cites similar examples from other languages. If frequency is not important and certain kinds of learning occur in a definite progression, then the crucial issue is to account for this learning and the progression. McNeill argues that the structure of language and of the child's mind controls the learning, whereas Slobin argues that the child's cognitive and mental capacities at each stage regulate his ability to learn. However, each agrees 
with the other that the relative frequency of stimuli is of little importance in language acquisition.

Imitation in the sense of modeling also holds an important place in behavioristic theories of learning in which some kind of modeling of behavior must occur. While there is evidence that children do practice language (Weir 1962) and do repeat some of the utterances of persons around them, they do not imitate indiscriminately. For example, Weir's child produced certain imitations but also made many variations on the imitated utterances. Babies do not imitate sounds in general, but they do respond quickly to human sounds. Lenneberg, Rebelsky, and Nichols (1965) also report that the prelinguistic vocalization behavior of deaf infants is not different from that of hearing infants. Therefore, imitation is not a critical factor in this very early stage of development, as it is, for example, in Jenkins and Palermo's theory. Menyuk (1963b) notes that the ability to imitate depends on the acquisition of some prior ability since children give evidence of various difficulties in imitating utterances. Utterances such as allgone shoe, allgone lettuce, and allgone vitamins reported by Braine (1963b) also argue against imitation and for some other ability, for no such sentences occurred in the environment of the child who produced them. Similar evidence is reported by Brown and Bellugi (1964) and by Miller and Ervin (1964).

One obvious constraint upon the child's ability to imitate is the limitation imposed by his short term memory span. It is also very difficult to explain how simple imitation leads to development. Obviously, some issue has been skirted. Young children are actually rather poor imitators, as McNeill (1966) shows in the following sample:

The signs are that sometimes a child's tendency to assimilate adult models into his current grammar is so strong that even when he makes a deliberate effort to copy adult speech, the effort may at first fail. One child, in the phase of producing double negatives while developing the negative transformation, had the following exchange with his mother:

Child: Nobody don't like me.

Mother: No, say "'nobody likes me."

Child: Nobody don't like me. 
(eight repetitions of this dialogue)

Mother: No, now listen carefully; say "nobody likes me."

Child: Oh! Nobody don't likes me.

The exchange is interesting because it demonstrates the relative impenetrability of the child's grammar to adult models, even under the instruction (given by the mother's "no") to change. The child behaves at first as if he did not perceive the difference between his mother's sentence and his own, though later, when the mother supplied great emphasis, the child recognized a distinction. With this much delay in introducing changes, spontaneous imitations are bound not to be grammatically progressive because they consist only of a single exchange. The fact that a change ultimately was made, however, illustrates that children can profit from adult models. (1966:69)

Mc Neill does not deny the importance of models to the child in his learning, but does show that simple imitation of such models provides an inadequate explanation of linguistic development. Ervin (1964) demonstrates that imitations by children are not grammatically progressive, for they are less complicated syntactically than concurrent free utterances. Menyuk (1963a), Lenneberg, Nichols, and Rosenberger (1964), and Slobin and Welsh (1967) all report that children produce in imitation only what they produce in spontaneous speech even to the extent of reducing adult-given sentences to the forms they are currently producing.

Still another difficulty with relying heavily on imitation in any theory of language acquisition is the fact that much of the speech to which the child is exposed is considerably fragmented. Yet he learns to filter out poor examples in forming his grammar. This accomplishment is at least as difficult to explain as is the accomplishment of being able to react to more complex utterances than he can produce. Some factor other than imitation must be involved in each case. Lenneberg (1962) points out one specific case in which imitation could not have been involved in language acquisition, that of a boy with a congenital motor disability that prevented him from speaking. However, since the same boy could understand complicated instructions, neither imitation nor reinforcement could be used to explain his abilities. The language of the environment in which the child finds himself is vitally important to him in his 
acquisition of language. But direct imitation of that language seems not to occur except in rather small amounts.

The role of expansion in language acquisition is a still more complicated issue. Parents do correct and expand the speech of their children. However, there is evidence that children are not particularly receptive to direct instruction in language, as is obvious in the quotation cited above from McNeill. Although corrections might be expected to extinguish certain undesirable linguistic behaviors, they are unlikely to promote desirable ones. Expansions might be helpful in stimulating linguistic development, and some agreement exists that middle-class mothers expand their children's speech about $30 \%$ of the time and that such use of expansion forms a part of the normal mother-child relationship. Cazden (1965) tested the hypothesis that expansions of children's utterances would aid language acquisition more than would comments on their utterances, which she called models, and that both would produce better results than no expansion or modeling responses. She divided twelve $2 \frac{1}{2}$ year-old children into three groups: the first group received intensive and deliberate expansions; the second group received qualitatively equal exposure to well-formed sentences that were models not expansions; and the third group received no special treatment at all. Her experiment lasted twelve weeks. The results do not show quite the expected differences in that modeling, not expansion, was more effective. That is, semantically-enriched responses were more effective than syntactically-enriched responses. However, a more recent study by Feldman and Rodgon (1970) reports results at variance with those of Cazden. In a further study, Brown, Cazden, and Bellugi (1968) analyzed the conversations of mothers and children aged one to four years to determine what happens during such conversations. They report that the syntactic correctness or incorrectness of a child's speech does not control the mother's approval or disapproval. Rather the truth or falsity of the utterance does. They conclude that parents tend to reward true statements and punish false ones; however, somewhat surprisingly, the result is the eventual production of syntactically correct sentences.

Deliberate expansion of children's language by adults would seem to be one of the most important possible influences on language development. However, the evidence does not confirm this hypothesis. Having considered the evidence from research in the use of both imitation and expansion, Slobin (1968) concludes that there is little evidence to support imitation. However, he takes a more positive attitude toward expansion: 
It has been suggested that frequency of parental expansion of child speech may be related to such variables as social class and education, and, in turn, be partly responsible for differences in language acquisition and ability in children of different socioeconomic backgrounds. The issue is certainly complex, and we are far from being able to determine the functions-if anyof expansion and imitation in the human child's remarkable acquisition of language. Until the necessary data are amassed, I would still like to believe that when a child hears an adult expansion of his own speech he learns something important about the structure of his language. (1968:443)

The results as a whole argue more for the acceptance of languageacquisition theories like those of Lenneberg, McNeill, and Slobin than they do for those of Braine and Staats and Staats, and more for the importance of some kind of innate linguistic or cognitive structure than of the actual stimuli encountered in the environment.

Studies of language acquisition tend to focus on the acquisition of phonology or syntax. The place and function of meaning in language acquisition have largely been ignored. However, meaning is today assuming greater importance in studies of language acquisition.

Following a comprehensive review of Russian data on language development in children, Slobin (1966a) suggests that the order of emergence of various syntactic categories depends on their relative semantic difficulty rather than on their grammatical complexity. The first grammatical distinctions to appear are those like the singular-plural distinction that make some concrete reference to the outside world. Later to emerge are the diminutive suffixes of nouns, imperatives, and categories based on relational criteria, such as the case, tense, and person markings of verbs. Conditional forms of the if-then variety are not learned until near the end of the third year. Still other abstract categories of quality and action continue to be added until the age of seven. Slobin argues that semantic complexity rather than grammatical difficulty determines the developmental sequence. Grammatical gender in Russian is the most difficult of all the categories for the child to master since it has almost no semantic correlates. No rules exist that the child can discover to make the learning easier, so the acquisition of gender is a long, drawn out process. Slobin concludes: "The semantic and conceptual aspects of grammatical classes thus clearly play an important role in determining the order of their development and subdivision." (1966a:142).

Telegraphic speech is full of "contentive" words. Slobin (1971: 44-46) shows some of the semantic range of telegraphic speech in 
various languages (English, German, Russian, Finnish, Luo, and Samoan). Following an analysis of such speech, a reexamination of the data from the pivot grammars of investigators such as Braine, and some work of her own, Bloom (1970, in press) argues that the evidence indicates that semantic competence outstrips syntactic competence. Her own research showed that noun-noun combinations in the speech of very young English children expressed at least the following five relations: conjunction (block dolly), attribution (party hat), genitive (daddy hat), subject-locative (sweater chair), and subject-object (mommy book). She also found that an utterance such as no truck could have various meanings, which themselves showed an order of emergence: "nonexistence" (There's no truck here) preceding "rejection" (I don't want a truck), which in turn precedes "denial" (It's not a truck; it's something else). She concludes that the child's underlying semantic competence is more differentiated than the surface forms of his utterances, because he is aware of more types of meaning relationships than he can reveal through the linguistic devices he controls. Before he develops these devices, his two-word utterances can be properly interpreted only through the use of the non-linguistic context. Quite often a young child must produce a series of short utterances in order to convey information that an adult or an older child expresses in a single utterance. For example, he might say raisin there/buy more grocery store / raisins / buy more grocery store/ grocery store/ raisin a grocery store instead of one sentence about buying more raisins at the grocery store. Consequently, Bloom (1970) claims that three components operate in the development of language competence: cognitive-perceptual development, linguistic experience, and non-linguistic experience. She notes that these components converge during the child's development.

\section{An Assessment of the Theories}

The studies reported by McCarthy encompass massive quantities of data but lack clearly defined theories of language acquisition. A concern for such theories is a fairly recent development in studies of language acquisition. However, all such theories have at least the weaknesses of lack of detail and lack of empirical validation. They are all very general, often being little more than series of claims about what must be, the claims being supported by reference to carefully selected data often acquired from no more than a few children. Consequently, they are often hardly any more convincing than former presentations of large quantities of data that really make no claims at all.

Recently proposed theories make either a language or learning 
component central. Making a language component central requires postulation of a strong innate predisposition toward the acquisition of very specific kinds of linguistic facts, for the child is assumed to "know" much about language in general before any learning of specific details begins. Environmental factors are relatively unimportant in such theories. On the other hand, older behavioristic learning theories hold the environment to be extremely important in providing language stimuli and controlling the learning that occurs. According to such theories, language acquisition is achieved through such processes as association and response generalization. The child makes little or no active contribution to the total process and learns language in much the same way as he learns anything else.

A less extreme position is that language acquisition is unique because language is different from anything else that is learned, but that the learning requires use of many of the same principles as other kinds of learning. In this case, the theory may have a large biological component that emphasizes the importance of certain kinds of universal neurological and physiological developments. Or it may assume the availability of this component and emphasize the kinds of meaningful situations that stimulate language acquisition and the cognitive limitations that human development places on the acquisition process. Unfortunately, since meaning has long been a stepchild in linguistics and cognitive theory a poor relation in psychology, it is difficult at present to fill out the details of any such theory.

An evaluation of the importance of such factors as frequency, imitation, and expansion in language acquisition leads to the rejection of any kind of monolithic behavioristic theory. However, it does not eliminate linguistically-based theories nor does it contradict cognitively-based ones. The evaluation reveals how unimportant each of the factors is in language acquisition, and indicates the necessity of crediting the child with some kind of innate knowledge or capacity. The difficulty with the innate knowledge hypothesis is that investigators like McNeill have very little to say about the mechanisms through which that knowledge reveals itself, nor do they try to relate language learning to other kinds of learning. The result is something less than a parsimonious view of total human development. The advantage of the innate capacity hypothesis is that general laws of learning, but not exclusively behavioristic ones, can be used to explain both language acquisition and other kinds of learning. Sachs (in press) summarizes this problem as follows:

Theories of language acquisition that consider only the linguistic aspect will not be able to explain why the child learns new forms 
when he does, or in fact why he ever changes his form of expression. It is only through more research on the complex relationship between cognitive development and language acquisition that we will have a full understanding of either. Hopefully in the future we will find more studies of this type, and a closer communication between psycholinguists and pyschologists studying other aspects of child development.

The linguistically-based theories all have one serious drawback in that they are concerned with the ideal child. Theories recognizing individual and group differences are ignored in favor of theories that try to account for the development of abstract linguistic competence. Social, motivational, and cultural variables are all ignored. The child is said to have acquired his basic linguistic competence by the age of five or six. While performance is acknowledged to vary from child to child, such variability, whatever its cause, is ignored, often under the guise of "performance" differences, which are at best of peripheral interest. The result is a deliberate biasing of the theories toward accommodating one set of factors in language acquisition and ignoring almost all others.

\section{LANGUAGE ACQUISITION AND BEGINNING READING}

Language Acquisition after Age Six

Although many linguists claim that the major part of language acquisition takes place in the years between the ages of one and four, children who enter school do not have the linguistic abilities of adults and the linguistic abilities of adults change, and sometimes develop, during their lives. It is of interest to know the precise differences between the linguistic abilities of children entering school and of adults. Numerous investigators have shown that significant language development still occurs in all children after the age of five or six, among them Harrell (1957), Strickland (1962), Loban (1963), Menyuk (1963b), and O'Donnell, Griffin, and Norris (1967).

In a recent study C. S. Chomsky (1969) points out several grammatical developments that occur during the years that follow six: a grasp of the difference between the eager to see and easy to see constructions; a realization that $a s k$ and tell require different syntactic constructions; the ability to handle relationship requiring and and although; and a control of pronominalizations. Kessel (1970) used a Piaget-type interview technique similar to that used by C.S. Chomsky in further work on some of the same problems. His study confirms her results but also reports evidence of a 
somewhat earlier mastery of the more complex constructions. Menyuk (1969) points out other examples in which a more complicated structure is learned later than a less complicated one. However, in every case it is possible to argue that the linguistic development has not occurred because the cognitive capacities of the child do not allow it rather than because the structure which is learned second is more complicated than the one which is learned first. Of course, since it is also possible to argue that the structure learned second is grammatically more complicated, the temptation is to postulate a linguistic rather than a cognitive constraint on development, particularly when the investigator is linguistically-oriented.

Two linguistic abilities that children of about age six appear to have are those to overdiscriminate and to overgeneralize. $\mathrm{N}$. Chomsky (1964) points out that they have very sharp abilities to discriminate among phonetically close stimuli. Miller and Ervin (1964) and Ervin (1964) say that they tend to eliminate from their language irregular but correct inflections in favor of regular but incorrect ones for a while. Slobin (in press), citing evidence mainly from Russian, discusses this same phenomenon, which he calls "inflectional imperialism."

Bever, Mehler, and Valian (1968) report that children aged two to four temporarily overgeneralize newly acquired semantic strategies. There is also some agreement that children do not interpret "same" and "different" in the way that mature adults do, nor are they able to work in a conscious analytic fashion with language, as many adults can. Slobin (in press) points out that the Russian data he analyzed provide evidence that any kind of direct instruction in the analysis of language is rather ineffective with children.

In one crucial area for any kind of reading instruction that relies on the relationship of individual sounds to symbols, the acquisition of phonology, six-year olds have not mastered the system that educated literate adults appear to have mastered (Chomsky and Halle 1968, C. S. Chomsky 1970). The abilities of the two groups appear to be quite different. Indeed language acquisition in this area appears to depend on the acquisition of the ability to read, but this is the only place where this particular dependency occurs.

\section{Some Important Differences Between Language Acquisition and}

\section{Beginning Reading}

Whatever theory of language acquisition an investigator subscribes to, behavioristic, nativistic, or cognitive, he must readily admit that important differences exist between the acquisition of language and the acquisition of beginning reading skills. Staats 
and Staats (1962), Carroll (1966), and Natchez (1967) are among those who point out some of the specific differences.

Language is acquired gradually and the acquisition process is probably never completed, for something always remains to be learned. The process is also one that had no conscious beginning point for the child. On the other hand, learning to read often has a sudden onset for children, although some are fortunate to avoid this kind of introduction. Even though some of the cognitive and motor skills necessary for reading have been developed for other activities, the child is often required to put them altogether rather abruptly, in learning to read in a formal school setting.

The level of anxiety in the context in which learning to read takes place may also be quite high: the anxiety of the parent, teacher, and the child. Little such anxiety is manifested during the process of learning to talk. Certainly, it is the rare child who exhibits anxiety, and, if the occasional parent is anxious about a particular child's speech, this anxiety seems to have little influence on the child's language development. There is also often a concomitant assignment of blame for any "failure" that occurs in beginning reading instruction. Children are not "blamed" when they fail to acquire language; rather they are given special help.

Reading instruction is very formal and deliberate. Language, however, is learned informally and unconsciously from a widerange of stimuli. No deliberate instruction is necessary. Language is not learned from programmed stimuli, from making conscious distinctions among stimuli, from learning "about" language, and from acquiring control of a variety of analytic and synthetic techniques. While controversy does exist as to the function of linguistic stimuli in language acquisition, there is agreement that such stimuli vary in both form and content in ways that are not well understood, but which the child is well able to handle.

The usual reinforcements experienced by literate adults for reading may be irrelevant for many children in the beginning reading stages: the benefits are often too abstract, distant, and meaningless, and the effort to be expended for such remote ends may seem to be quite wasteful and unpleasant to the child. On the other hand, the benefits of learning to speak are too obvious to mention.

The two activities are also different in certain other ways. Learning to read depends on the acquisition of special skills in visual discrimination. The redundancies in the two language systems that are involved are also different, as is quite often the content, that is, the meanings that are conveyed. Writing is not simply speech written down: it is more abstract than speech in content; it usually employs carefully edited and controlled language 
for different reasons from speaking; and it functions rather differently in the lives of the recipients of the message. Vygotsky (1962) writes as follows on these very points, but in connection with writing rather than reading:

Written speech is a separate linguistic function, differing from oral speech in both structure and mode of functioning. Even its minimal development requires a high level of abstraction....

Our studies show that it is the abstract quality of written language that is the main stumbling block, not the underdevelopment of small muscles or any other mechanical obstacles.

Writing is also speech without an interloctor, addressed to an absent or an imaginary person or to no one in particular-a situation new and strange to the child. Our studies show that he has little motivation to learn writing when we begin to teach it. He feels no need for it and has only a vague idea of its usefulness. In conversation, every sentence is prompted by a motive. Desire or need lead to request, question to answer, bewilderment to explanation. The changing motives of the interlocutors determine at every moment the turn oral speech will take. It does not have to be consciously directed-the dynamic situation takes care of that. The motives for writing are more abstract, more intellectualized, further removed from immediate needs. In written speech, we are obliged to create the situation, to represent it to ourselves. This demands detachment from the actual situation.

Writing also requires deliberate analytical action on the part of the child. In speaking, he is hardly conscious of the sounds he pronounces and quite unconscious of the mental operations he performs. In writing, he must take cognizance of the sound structure of each word, dissect it, and reproduce it in alphabetical symbols, which he must have studied and memorized before. (1962:98-99)

Reid (1966), Meltzer and Herse (1969), and Downing (1970) all point to the confusion that children often experience in learning to read. Evidently, many children do not understand what reading is, or what they are supposed to be doing, or what the terms mean that are used in the instructional process.

The usual methods of reading instruction employ imitation, repetition, control of stimuli, correction, and expansion, exactly those factors examined earlier in relation to the acquisition of language. These factors were found not to be very important in language acquisition; however, they are very important in reading instruction. Of course, instruction implies some kind of method- 
ology, so the reason for their existence is obvious. Yet, it would be well to subject that methdology to periodic critical assessment in the light of the latest findings from relevant disciplines. Of course, one can also argue that since language acquisition and learning to read are quite different tasks, these factors may still be important in the teaching of beginning reading.

Finally, language acquisition does not cease at the age six. Consequently, some kinds of acquisition overlap with learning to read. However, little is known about the extent of this overlap, for the later stages of language acquisition are even more of a mystery than are the earlier stages. It may be that more than one of these stages depends on the child's acquiring certain reading abilities just as beginning reading ability quite definitely depends on the acquisition of considerable linguistic competence. However, this acquisition has occurred in six-year olds except in rare pathological cases.

\section{CONCLUSION}

The theories of language acquisition that are available to us today are largely irrelevant in deciding issues in beginning reading instruction or even in devising models of the reading process. Moreover, reading failure cannot easily be linked to deficiencies in language acquisition, for children who are asked to learn to read are almost invariably well on the way to linguistic maturity.

Reading methods themselves are almost unrelated to theories of language acquisition. Both phonics and whole-word methods depend on the possession of certain language abilities which all children of six apparently do have. What they might not have are some of the cognitive abilities that the methods require: abilities to make certain kinds of discriminations, to form generalizations, and to verbalize knowledge. Furthermore, much of what is taught "about" language in such methods is antiquated and not very useful to anyone, particularly to six-year olds.

Reading is often taught to improve language. Research has long demonstrated that such teaching is generally ineffective. Some linguistic skills apparently derive from the acquisition of the skills of literacy, but these skills appear to be few and certainly do not seem to be acquired during the critical period of beginning reading instruction. 


\section{REFERENCES}

Bever, T. G., Fodor, J. A., and Weksel, W. 1965a. Is linguistics empirical? Psychological Review 72.492-500.

Bever, T. G., Fodor, J. A., and Weksel, W. 1965b. On the acquisition of syntax: A critique of "contextual generalization." Psychological Review 72.467-482.

Bever, T. G., Mehler, J. R., and Valian, V. V. 1968. Linguistic capacity of very young children. Unpublished manuscript, ERIC ED 018-796.

Bloom, L. 1970. Language Development: Form and Function in Emerging Grammars. Cambridge, Mass.: M.I.T. Press.

Bloom, L. Why not pivot grammar? The Journal of Speech and Hearing Disorders, (in press).

Braine, M.D.S. 1963a. On learning the grammatical order of words. Psychological Review 70.323-348.

Braine, M.D.S. 1963b. The ontogeny of English phrase structure: the first phase. Language 39.1-13.

Braine, M.D.S. 1965. On the basis of phrase structure: a reply to Bever, Fodor, and Weksel. Psychological Review 72.483-492.

Brown, R. 1965. Social Psychology. New York: Free Press.

Brown, R., and Bellugi, U. 1964. Three processes in the child's acquisition of syntax. Harvard Educational Review 34.133-151.

Brown, R., and Berko, J. 1960. Psycholinguistic research methods. In P. H. Mussen (Ed.), Handbook of Research Methods in Child Development. New York: Wiley \& Sons.

Brown, R., Cazden, C. B., and Bellugi, U. 1968. The child's grammar from 1 to 3. In J. P. Hill (Ed.), The 1967 Minnesota Symposium on Child Psychology. Minneapolis: University of Minnesota Press.

Carroll, J. B. 1966. Language development in children. In Encyclopedia of Educational Research. 744-750. New York: Macmillan.

Carroll, J. B. 1966. Some neglected relationships in reading and language learning. Elementary English 43,577-582.

Cazden, C. B. 1965. Environmental assistance to the child's acquisition of grammar. Unpublished doctoral dissertation. Harvard University.

Chomsky, C. S. 1969. The acquisition of syntax in children from 5 to 10. Cambridge, Mass.: M.I.T. Press.

Chomsky, C.S. 1970. Reading, writing, and phonology. Harvard Educational Review 40.287-309.

Chomsky, N. 1957. Syntactic Structures. The Hague: Mouton.

Chomsky, N. 1959. Review of B. F. Skinner, Verbal Behavior. Language $35.26-58$.

Chomsky, N. 1964. Comments for project literacy meeting. Project Literacy Reports 2.1-8.

Chomsky, N. 1965. Aspects of the Theory of Syntax. Cambridge, Mass.: M.I.T. Press.

Chomsky, N., and Halle, M. 1968. The Sound Pattern of English. New York: Harper \& Row.

Cromer, R. 1968. The development of temporal references during the acquisition of language. Unpublished doctoral dissertation. Harvard University.

Downing, J. 1970. The development of linguistic concepts in children's thinking. Research in the Teaching of English. 4.1.5-19. 
Elkonin, D. B. 1958. Razvitie Rechi v. Doshkol'nom vozraste. (The Development of Speech in Preschool Age.) Moscow: Akad. Pedag. Nauk RSFSR.

Ervin, S. M. 1964. Imitation and the structural change in children's language. In E. H. Lenneberg (Ed.), New Directions in the Study of Language. Cambridge, Mass.: M.I.T. Press.

Ervin-Tripp, S. M. 1966. Language development. In M. Hoffman and L. Hoffman (Eds.), Review of Child Development Research 2. Ann Arbor: University of Michigan Press.

Ervin-Tripp, S. M., and Slobin, D. I. 1966. Psycholinguistics. Annual Review of Psychology 17.435-474.

Feldman, C. F., and Rodgon, M. 1970. The effects of various types of adults' responses in the syntactic acquisition of two- to three-year olds. Unpublished paper. Department of Psychology, University of Chicago.

Fodor, J. A. 1966. How to learn to talk: some simple ways. In F. Smith and G. A. Miller (Eds.), The Genesis of Language: A Psycholinguistic Approach. Cambridge, Mass.: M.I.T. Press.

Garrett, M., and Fodor, J. A. 1968. Psychological theories and linguistic constructs. In T. R. Dixon and D. I. Horton (Eds.), Verbal Behavior and General Behavior Theory. Englewood Cliffs, N.J.: Prentice-Hall.

Harrell, L. E., Jr. 1957. An inter-comparison of the quality and rate of the development of the oral and written language in children. (Monographs of the Society for Research in Child Development 22.)

Jenkins, J. and Palermo, D. 1964. Mediation processes and the acquisition of linguistic structure. In U. Bellugi and R. W. Brown (Eds.), The Acquisition of Language. (Monographs of the Society for Research in Child Development 29.1, Serial No.92).

Kelley, K. L. 1967. Early Syntactic Acquisition. Santa Monica, Calif.: The Rand Corporation.

Kessel, F. S. 1970. The role of syntax in children's comprehension from ages six to twelve. (Monographs of the Society for Research in Child Development 35.6, (Serial No. 139).

Klima, E. S., and Bellugi, U. 1966. Syntactic regularities in the speech of children. In J. Lyons and R. Wales (Eds.), Psycholinguistic Papers. Edinburgh: Edinburgh University Press.

Lenneberg, E. H. 1962. Understanding language without the ability to speak: a case report. Journal of Abnormal Social Psychology 65.419-425.

Lenneberg, E. H. 1967. Biological Foundations of Language. New York: Wiley \& Sons.

Lenneberg, E. H., Nichols, I. A., and Rosenberger, E. F. 1964. Primitive stages of language development in mongolism. Proc. Assoc. Res. Nerv. Ment. Disease 42.119-137.

Lenneberg, E. H., Rebelsky, F. G., and Nichols, I. A. 1965. The vocalization of infants born to deaf and to hearing parents. Vita Humana $\mathrm{Hu}$ man Development) 8.23-37.

Loban, W. D. 1963. The Language of Elementary School Children. Champaign, Ill.: National Council of Teachers of English.

Mc Carthy, D. 1954. Language development in children. In L. Carmichael (Ed.), Manual of Child Psychology. New York: Wiley.

McNeill, D. 1966. Developmental psycholinguistics. In F. Smith and G. A. Miller (Eds.), The Genesis of Language: A Psycholinguistic Approach. Cambridge, Mass.: M.I.T. Press. 
McNeill, D. 1968. On the theories of language acquisition. In T. R. Dixon and D. L. Horton (Eds.), Verbal Behavior and General Behavior Theory. Englewood Cliffs, N.J.: Prentice-Hall.

McNeill, D. 1970a. The Acquisition of Language: The Study of Developmental Psycholinguistics. New York: Harper \& Row.

MeNeill, D. $1970 \mathrm{~b}$. The development of language. In P. A. Mussen (Ed.), Carmichael's Manual of Child Psychology. New York: Wiley.

Meltzer, N. S., and Herse, R. 1969. The boundaries of written words as seen by first graders. Journal of Reading Behavior 1.3-14.

Menyuk, P. 1963a. A preliminary evaluation of grammatical capacity in children. Journal of Verbal Learning and Verbal Behavior 2.429-439.

Menyuk, P. 1963b. Syntactic structures in the language of children. Child Development 34.407-422.

Menyuk, P. 1969. Sentences Children Use. Cambridge, Mass.: M.I.T. Press.

Miller, W., and Ervin, S. M. 1964. The development of grammar in child language. In U. Bellugi and R. Brown (Eds.), The Acquisition of Language. (Monographs of the Society for Research in Child Development 29.1 , Serial No. 92).

Natchez, G. 1967. From talking to reading without really trying. The Reading 'Teacher 20.339-342.

O'Donnell, R. C., Griffin, W. J., and Norris, R. C. 1967. Syntax of Kindergarten and Elementary School Children: A Transformational Analysis. Champaign, Ill.: National Council of Teachers of English.

Reid, J. F. 1966. Learning to think about reading. Educational Research 9.56-62.

Sachs, J. 1971. The status of developmental studies of language. In J. Eliot (Ed.), Human Development and Cognitive Processes. New York: Holt, Rinehart \& Winston.

Schlesinger, I. M. Production of utterance and language acquisition. In D. I. Slobin (Ed.), The Ontogenesis of Grammar: Facts and Theories. New York: Academic Press, in press.

Sinclair-de Zwart, H. 1968. Sensorimotor action schemes as a condition of the acquisition of syntax. Unpublished paper, University of Geneva.

Slobin, D. I. 1966a. The acquisition of Russian as a native language. In F. Smith and G. A. Miller (Eds.), The Genesis of Language: A Psycholinguistic Approach. Cambridge, Mass.: M.I.T. Press.

Slobin, D. I. 1966b. Comments on "Developmental psycholinguistics." In F. Smith and G. A. Miller (Eds.), The Genesis of Language: A Psycholinguistic Approach. Cambridge, Mass.: M.I.T. Press.

Slobin, D. I. 1968. Imitation and grammatical development. In N. S. Endler, L. R. Boulter, and H. Osser (Eds.), Contemporary Issues in Developmental Psychology. New York: Holt, Rinehart \& Winston.

Slobin, D. I. 1970. Universals of grammatical development in children. In G. B. Flores d'A rcais and W. J. M. Levelt (Eds.), Advances in Psycholinguistics. Amsterdam-London: North Holland Publishing Company.

Slobin, D. I. 1971. Psycholinguistics. Glenview, Ill.: Scott, Foresman.

Slobin, D. I. Early grammatical development in several languages, with special attention to Soviet research. In T. G. Bever and W. Weksel (Eds.) The Structure and Psychology of Language. New York: Holt, Rinehart \& Winston, in press. 
Slobin, D. I., and Welsh, C. A. 1967. Elicited imitation as a research tool in developmental psycholinguistics. Unpublished paper, Department of Psychology, University of California, Berkeley.

Staats, A. W., and Staats, C. K. 1962. A comparison of the development of speech and reading behavior with implications for research. Child Development 33.831-846.

Staats, A. W., and Staats, C. K. 1963. Complex Human Behavior: A systematic Extension of Learning Principles. New York: Holt, Rinehart \& Winston.

Staats, A. W., and Staats, C. K. 1968. Language, Learning, and Cognition. New York: Holt, Rinehart, \& Winston.

Strickland, R. G. 1962. The language of elementary school children: its relationship to the language of reading textbooks and the quality of reading of selected children. Bulletin of the School of Education 38. Bloomington, Ind.: Indiana University.

Vygotsky, L. S. 1962. Thought and Language. Cambridge, Mass.: M.I.T. Press.

Weir, R. 1962. Language in the Crib. The Hague: Mouton.

Weksel, W. 1965. Review of U. Bellugi and R. Brown (Eds.), The acquisition of language. Language 41.692-709. 